$$
f=\frac{1}{r_{0}} \int_{-2}^{x^{\prime}} h(x) d x
$$

を求める。厚い場合，溥い場合には計算によって求め た $h(u)$ を用いて $p$ を求める。このとき $f=-p$ の関 係がある。対称な配置の埸合には (3・36), (3・37) よ り, $\delta$ を最小とする場合には $(3 \cdot 34),(3 \cdot 35)$ から $\mathrm{S}^{\prime}$, $\mathrm{S}^{\prime \prime}$ の境界面からの距離 $\boldsymbol{x}^{\prime}, \boldsymbol{x}_{1}{ }_{1} \cdot 2$ が求められる。スリ ット軸の位置は $(3 \cdot 23),(3 \cdot 31)$ より $s_{0}, R$ を求め (3・32) Kて実際の磁極片の頂点 $\mathrm{P}^{\prime}$ からの距離 $D$ を 求める。計算結果の一例老示す。刘称のとき, $r_{0}=22.0$ として

$$
\text { 碔作した磁石のとき }\left\{\begin{array}{l}
x^{\prime}=40.20 \\
s_{0}=1.40 \\
D=19.17
\end{array}\right.
$$

厚いとき

$$
\left\{\begin{array}{l}
x^{\prime}=40.90 \\
s_{0}=1.46 \\
D=18.06
\end{array}\right.
$$

溥いとき

$$
\left\{\begin{array}{l}
x^{\prime}=39.90 \\
s_{0}=0.87 \\
D=19.58
\end{array}\right.
$$

$\delta$ が最小になる場合の $\delta$ はほぼ $0.98 r_{0} \bar{a}^{2}$ の程度で むるから対称の場合の $\delta$ と实用上差はないと考えられ る。したがって，試作した磁石の場合 $x^{\prime}=36 \sim 40$ の

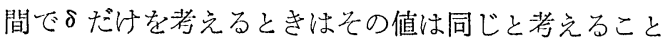
が出来る。
6. 結 言

本報告にては端縁磁界を考えたビームの氖際の軌道 の計算方法，扣よび計算式を示した。磁極片が厚い埸 合, 薄い場合扣よび試作した磁石（厚さは磁極間䏚の 2.5倍）について計算した結果を示した。Nier の端縁 磁界の補正法と比較した結果, この場合は対称となる が，スリット軸は Nier の示した位置よりやや磁極片 頂点から遠くに置く必琶があること，またCoggeshall の方法と比較した絬果は，その配置が対称にならない。 このときの像の位置を求めた。

分析計設計に関する一つの資料が得られた。試作し た磁石の磁界测定については本教室の助可小宮, 俳滕 の闻君の援助に感謝与る。

\section{文献}

1) R. Herzog, Z. Physik, 89447 (1934).

2) W. E. Stephens, Phys. Rev., 45513 (1934).

3) A. O. Nier, Rev. Sci. Inst., 11212 (1940).

4) N. D. Coggeshall J. Appl. Phys., 18855 (1947).

5) 谷安正 静電場 (応用数学) p. 132 (1942) 河出 書厚

6) N. D. Coggeshall and M. Muskat, Phys. Rev., 66187 (1944).

\title{
速度変調型質量分析装置 \\ Velocity Modulation Type Mass Spectrograph
}

\author{
江 副 博 彦*. 林友 直*
}

Hirohiko Ezoe, Tomonao Hayashi

(1958年12月26日受理)

\begin{abstract}
A non-magnetic velocity modulation type mass spectrograph is proposed, in which the bunching effect of the velocity-modulated ion beams is applied as $R$. $R$. Wilson had published in his report on the Isotron. While the Isotron handles a bunch of an isotope formed at a definite position in space, in the present paper the problems on the recording of the mass spectrum consisting of the spatially distributed bunches are discussed. The neces sary applied voltages, frequencies, and geometrical dimensions for practical uses are also calculated.
\end{abstract}

\section{1. 緒・言}

磁界を用いない質量分析装置としてはW. E. Stephens $^{1)}$, W. H. Bennett ${ }^{2)}$, R. R. Wilson ${ }^{3)}$ 等のものがよ く知られている。以下述べる質量分析装置は Wilson
が Isotron の原理として採用したのと同じく速度変調

* 理化学研究所 (東京都交京区駒込上富士町31)

Rikagaku Kenkyusho (The Institute of Physical and Chemical Research, 31 Kamifujimae-cho, Komagome, Bunkyo-ku, Tokyo). 
によってイオンが集群する性質を利用したものである が，Isotron では空間の特定の位置に特定のイオンを 集群させてこれをイオンの飛行方向の端に設けたコレ クターに集めるように考えられているのに対して，こ こでは速度変調の結果空間に質量別にイオンの集群が ならんでできる澌量スペクトルに注目してその性質を 昑训し，このスペクトルをそのままイオン流と直角の 方向に引きつけて記録したときに得られる像について 検討を加えた。

\section{2. 原理}

Fig. 1 は装置の構成図である。イオン源を出て電王

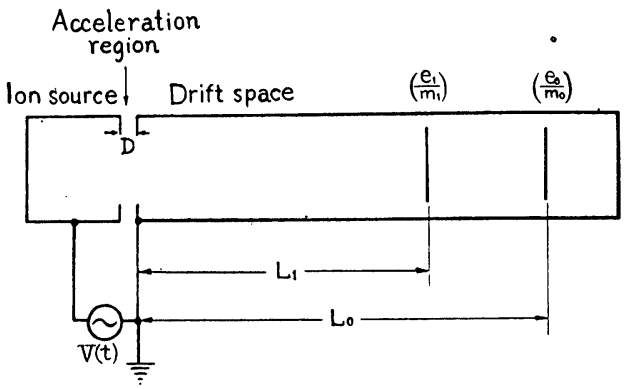

Fig. 1. Schematic representation of velocity modulation type mass spectrograph.

$V(\boldsymbol{t})$ で加速されたイオンは電界のない走行空間を進 行する。時刻 $t$ に走行空間に入った電荷 $e_{0}$, 質量 $\boldsymbol{m}_{0}$ のイオンが $T$ の時刻に $t$ に関係なく距離 $L_{0}$ の位置に 集群するためには，その速度 $v_{0}(t)$ は次の関係を満足 しなければならない。

$$
v_{0}(t)=\frac{L_{0}}{T-t}
$$

したがって，このときの加速電正 $V(t)$ は

$$
\frac{1}{2} m_{0} v_{0}(t)^{2}=e_{0} V(t)
$$

の関係が成立するとして

$$
V(t)=V(0) \cdot \frac{T^{2}}{(T-t)^{2}}
$$

となることがわかる。ここで

$$
V(0)=-\frac{m_{0}}{2 e_{0}} \cdot \frac{L_{0}^{2}}{T^{2}}
$$

多なわた

$$
T=\frac{L_{0}}{\sqrt{\frac{2 e_{0}}{m_{0}} V(0)}}
$$

である。

さて，(3)式にしたがう電国で加速されるイオン洔す べて時刻 $T$ の瞬間に集眸するのであって，電荷 $e_{1}$, 質 量 $m_{1}$ のイオンが加速されると

* 加速間隙 $D$ が距離 $L_{0}$ にくらべて十分に小さいときは近似 的に (2) 式が成立する。

$$
V(0)=\frac{m_{1}}{2 e_{1}} \cdot \frac{L^{2}}{T^{2}}
$$

を満足する距離 $L_{1}$,すなわち

$$
L_{1}=L_{0} \sqrt{\frac{e_{1}}{e_{0}} \cdot \frac{m_{0}}{m_{1}}}
$$

の位置に集群する。

以上の過程を図示すると Fig. 2 のようになるが, これは加速電生 $V(t)$ によってイオン流が速度变調を らけて, 先に出た遅いイオンに後から出た速いイオン がある一定の位置で追い付くことを示している。この

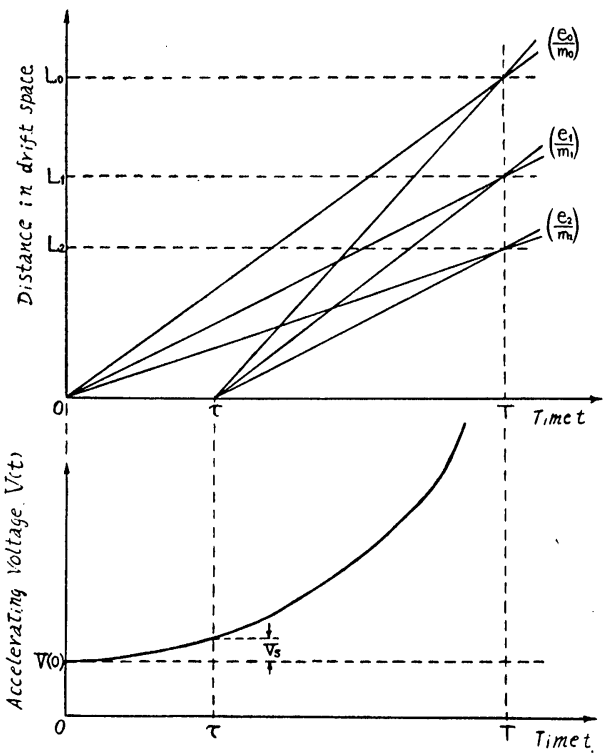

Fig. 2. Diagram showing the trajectories of the ions having different specific charges.

ようにして時刻 $T$ の瞬間にイオンは比電荷别に集群し， 走行空間の中で質量スペクトルを形成することになる。 のである。

なお， $0 \leqslant t \leqslant \tau$ の螌囲内の $V(t)$ を問期 $T$ で繰这 せば，比電荷の異なるイオンは走行空間内の关れぞれ に固有の位置に周期 $\boldsymbol{T}$ で集群する。このときの加速電 非直流加速電生 $V(0)$ の上に一種の鋸米状波電压を

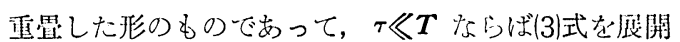
ᄂて

$$
\begin{aligned}
V(t) & =V(0)\left(1+\frac{2}{T} t+\frac{3}{T^{2}} t^{2}+\cdots \cdots\right. \\
& \left.+\frac{n+1}{T^{n}} t^{n}+\cdots \cdots\right)
\end{aligned}
$$

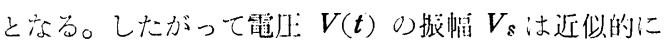

$$
V_{s}=V(\tau)-V(0) \fallingdotseq V(0) \cdot \frac{2 \tau}{T}
$$

と表わされる。

走行空間内に形成され合スペクトルの取出し力とし 七は種々の才式が考光られるが，最る基本的なものの 一例として次の方法が问能で女るう。すなわち, 占行 
空間の全長にわたりイオン流をはさんでとれに平行な 刘向平面電極を扣き，一方の上に写真乾板をおいて， 極板間に適当な位相と極性をもった幅の狭い高電王パ ルスを周期 $T$ で加えれば，乾板上に質量スペクトルを 䛉録することができるはずである。そこで以下この方 法について分解能を求めてみよう。

\section{3. 分 解 能}

簡単のためイオンはすべて 1 価であるとし，またイ

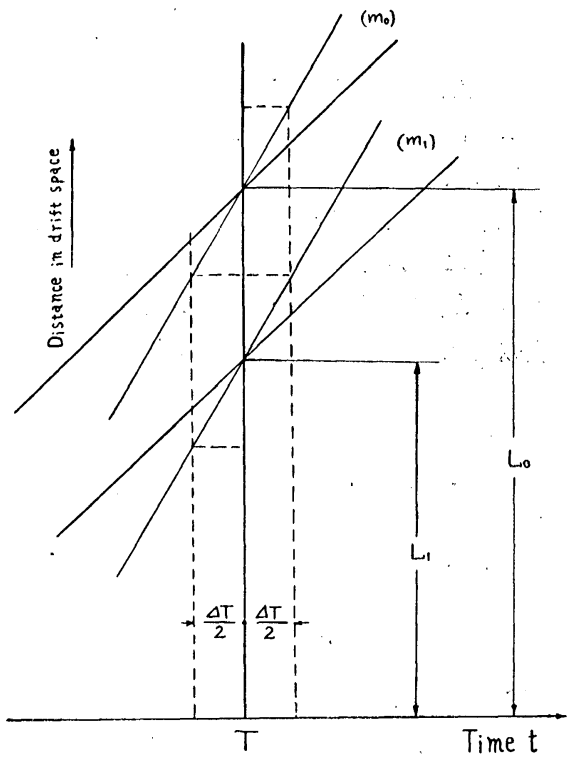

(a) Ideal case
でなければならないことがわかる。

一方, 加速電王に(3)式の近似として(8)式の第 2 項ま でとるものとすると，イオンの集群点附近の様子は Fig. 3 (b)のようになり, 時刻 $T$ でるスペクトル $\Delta L_{0} / L_{0}=\Delta L_{1} / L_{1}=\cdots \cdots=(3 / 2)(\tau / T)^{2}$ だけの幅が現 われる。これは $\tau$ にいて 1 次収斂である。この場合 も前と同様に検出用電生パルスの位相に $\pm \Delta T / 2$ の らぎがあるとすれば，(10)式に㥵当する式は次のよう火 なる。

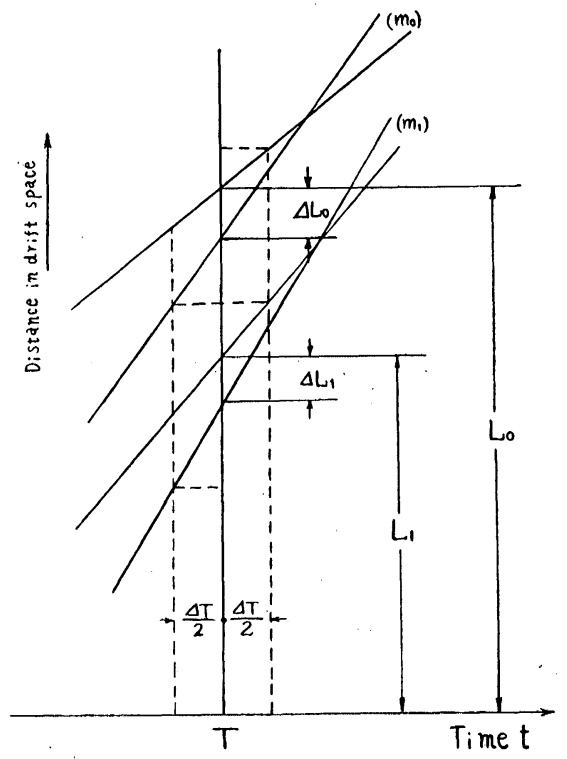

(b) 1st order phase focusing

Fig. 3. Diagram showing the resolving power in the presence of the phase fluctuation of detecting pulses.

オンの初速度は一応 0 と仮定する。

い木加速電圧として(3)式にしたがう波形を $0 \leqslant t \leqslant \tau$ について周期 $\boldsymbol{T}$ で繰返し加劣ると, 㫦群点附近に括け るイオンの走行距離と時間の関係は Fig. 3 (a)のよ うになって，空間電荷効果を無視する限り時刻 $\boldsymbol{T}$ では 完全に一点に集群する。しかしここで図に示したよう に，スペクトル梌出用の電圧パルスの位相にゆらぎが まって, 時刻 $T$ の前後に士 $\frac{\Delta T}{2}$ の幅で変動するもの と考えると，録されるスペクトルには幅を生ずる。 いま質量 $m_{0}$ のイオンのスペクトルの近端と,これに 隣接する質量 $m_{1}\left(=m_{0}+\Delta m\right)$ のイオンのスペクトル り遠端とがつながるところで分解能を定義すれいば，簡 単な計算から両者が分離できるためには

$$
\frac{\Delta m}{m_{0}} \geqslant \frac{2}{1-\frac{\tau}{T}}\left(\frac{\Delta T}{T}\right)
$$

$$
\begin{gathered}
\frac{\Delta m}{m_{0}} \geqslant 3\left(\frac{\tau}{T}\right)^{2}+\frac{2-\frac{T}{T}}{1-\frac{T}{T}}\left(\frac{\Delta T}{T}\right) \\
+\left\{\frac{\Delta T}{T} \text { の } 2 \text { 乘以上の項 }\right\}
\end{gathered}
$$

また加速電玨波形の近似をさらに進めて(8)式の第 3 項までとれば，時刻 $T$ におけるスペクトルの幅は $\Delta L_{0} / L_{0}=\Delta L_{1} / L_{1}=\cdots \cdots=2(\tau / T)^{3}$ となっててについて 2 次の収斂を示し, 検出用電庄パルスのゆらぎ士 $\Delta T / 2$ に対する分解能については次式が得られる。

$$
\begin{gathered}
\frac{\Delta m}{m_{0}} \geqslant 4\left(\frac{\tau}{T}\right)^{3}+\frac{2-\frac{\tau}{T}}{1-\frac{\Delta T}{T}}\left(\frac{\Delta T}{T}\right) \\
+\left\{\frac{\Delta T}{T} \text { の } \frac{3}{2} \text { 再以上の項 }\right\} \\
\text { なお, ここで } \Delta T \text { (12) }
\end{gathered}
$$


ぎとして等入したが，実際にはイオンの初速度分布や 加速電圧の変動に基づく走行時間のゆらぎもこれに念 めて考えることができる。

以上の計算では検出用電極に加えるパルス電生の大 きさは無限大として，集群したイオンはその分布のま 宋電極上の乾板に蹃きつけられると考元てきた。しか し资際には㭘出用パルス電压の大きさ怡有限であるか ら，Fig. 4 に示したように，集群点に佂けるエネル ギーのひろがり怙よびイオン流柬の厚みのために乾板 上湟られるスペクトル線の幅が增して，分解能がそ れだけ下ること苍考えなければならない。これを前に

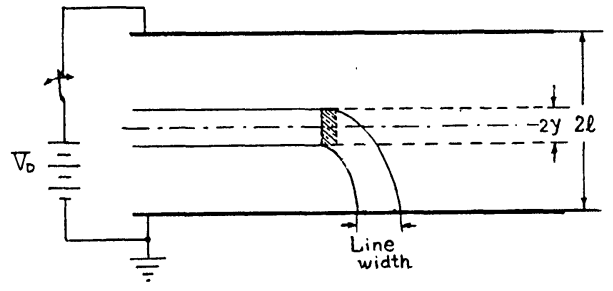

Fig. 4. Diagram showing the recorded line width due to aberration, beam thickness, and energy spread.

かッ舛た分解能を紫党る式(10)，(11)，扩小び(12)について い克ば，各式の㳡にとれぞれ正の項が道加されるこ とになる。どれらの值は Fig. 3 および Fig. 4 考用い て，尖群ならびに検出の各種の状況に応じて算出する ことができるが，榆出用電極の間陌を $2 l ，$ イオン流将 り原さを $2 \boldsymbol{y}$ として

$$
1>-\frac{y}{l} \gg-\frac{\tau}{T}
$$

となるように賭值をえりべば，近似啲にはこ水ら附加 項はいずれも

$$
\alpha=4 \sqrt{\frac{2 V(0)}{V D}} \cdot \frac{y}{L_{0}}
$$

とあらわされる。ここで $V D$ は検出用パルス電成の大 きさである。(13)式は集群点においてイオンのエネルギ 一の搪がりが無視できる条件であって，その結果は(14) 式の示すようにイオン流束の原みが分解能を下げる主 因として残るのである。たとえば $\boldsymbol{y}=0.25 \mathrm{~cm}, l=$ $0.5 \mathrm{~cm}, L_{0}=100 \mathrm{~cm}, V(0)=1 \mathrm{KV}, V D=50 \mathrm{KV}$ とし,
また $\tau / T=0.1$ にすれば(13)式の条件が成立すると考え られて， $\alpha$ の值は約 $1 / 500$ となる。

\section{4. 数 值 例}

本装置を実現しょうとする場合に，実際面からの裂 求としては，次のような事項が考元られる。すなわち

（1）分析管の長さ $L_{0}$ が長すぎないこと，

（2）質量分散 $L_{0}-L_{1}$ がかなり大きいこと,

(3) 加速電生 $V(0), V_{s}$ が高すぎないこと,

(4) ての値が小さすぎないこと,

(5) 訢谷されるゆらぎ $\Delta T$ がなるべく大きいこと。

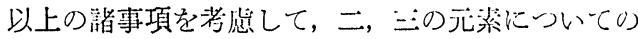
設計数值例を寺すと Table I のようになる。ただし， ここでは簡単のために众出用電生パルスの大きさ $V D$

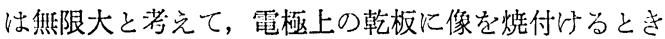
に生ずる線幅の增大は然いものとしてある。 ${ }^{4} \mathrm{He}-\mathrm{D}_{2}$ の埸合について 1 次収歛と 2 次収歛の例をかがげてを 当が， $L_{0}$ と $V(0)$ を与えて $T$ の値が決まると， 1 次 収歛では $\tau$ の值が小さくなってそれだけ灾現が困難で ある。ここで $V(0)$ の值を下げれば $T$ が大きくなっ ててが大きくとれるが，一般に(11)打よび(12)式か门明り 标なように，1次收歛では 2 次收歛に比べて常に $\tau / T$ ○值を㺫成り小さく保つことが必紧で，艺れだけ帒尘 したイオンの利用淬がわるいことに灾号。

\section{5. 結論}

Table I に示されているようにここの式はさして

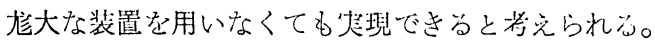
集群イオン検出の方式については種々あり得るが，こ の装置全体としてみたとき多少問题があると思われる 点は, 加速部では变调波形の䊑度, 梌出部では電山: ルスの位相の安定度である。变調波形は 1 次収歛の埸 合には単に直線的鋸歯状波を报らわけであるから，鋸 函状波回路の制御を適当に行えばかなり精度を上げる ことができる。2 次収歛以上の坯合には 1 次収斂のと きの方式に適当な科分回路を組合せる必要がある。ま た検出パルスに関しては立上り時間が短かく位㥵の安 定なものが望ましいわけであるが，ミリマイクロ秒領

\begin{tabular}{|c|c|c|c|c|c|c|c|c|c|c|c|c|c|c|c|}
\hline & & Parameters & Mo & $\mathrm{M}_{1}$ & Lo & Lo- $_{1}$ & $\mathrm{~V}(\mathrm{O})$ & $\tau / T$ & Vs & $\mathrm{T}$ & $\tau$ & $\Delta \mathrm{T} / \mathrm{T}$ & $\Delta \mathrm{T}$ & & $\begin{array}{l}\text { Phase } \\
\text { focusing }\end{array}$ \\
\hline Ions & & Units & $\mathrm{amu}$ & $\mathrm{amu}$ & $\mathrm{m}$ & $\mathrm{mm}$ & $k \mathrm{~V}$ & & $\mathbf{v}$ & $\mu_{\mathrm{sec}}$ & $\mu_{\mathrm{sec}}$ & & $m \mu \mathrm{sec}$ & & \\
\hline & ${ }^{235} \mathrm{U}$ &,${ }^{238} \mathrm{U}$ & 235 & 238 & 2 & 12.8 & 2 & $1 / 30$ & 133 & 49. 3 & 1. 64 & $1 / 200$ & 240 & & $1 s t$ \\
\hline & ${ }^{6} \mathrm{Li}$ & , ${ }^{7} \mathrm{Li}$ & 6 & 7 & 1 & 83 & 1 & $1 / 10$ & 200 & 5.6 & 0.56 & $1 / 15$ & 360 & & $1 \mathrm{st}$ \\
\hline & ${ }^{4} \mathrm{He}$ & , $\quad \mathrm{D}_{2}$ & 4. 004 & 4. 029 & 3.2 & 10 & 1 & $1 / 30$ & 67 & 14. 7 & 0.49 & $1 / 700$ & 21.0 & & 1 st \\
\hline & ${ }^{4} \mathrm{He}$ & , $\quad \mathrm{D}_{2}$ & 4. 004 & 4. 029 & 3.2 & 10 & 1 & $1 / 10$ & 200 & 14. 7 & 1. 47 & $1 / 940$ & 15.6 & & $2 n d$ \\
\hline
\end{tabular}

Table I. Design Data 

報
文
域のパルス技術を用いればこれも解決できるであろう。
上は単に原理的な計算であって, 今後は実験を行いつ
この方式の利点としてはスリット系を必要としない つさらに検討を加えて行きたいと思う。
ことで，そのため機械的な工作精度がさほど要求され ないばかりでなく，イオンの利用率が非常に高くとれ るものと思われる。おたここでは写真乾板を置いて装 置を質量分析器として使う場合を考えたのであるが, 適当にイオンコレクターを配置すれば質量分析計とし ても使光ようし，末たイオン量を豊富にできることか

\section{文献}
1) W. E. Stephens: Phys. Rev., 69, 691 (1946).
2) W. H. Bennett: J. App. Phys., 21, 143 (1950).
3) R. R. Wilson: AECD-3373, May 19, (1952). (昭和33年11月14日質量分析研究会講演会飞発表) ら分離器として用いることも考克られ小う。しかし以

\title{
質量分析計用微量気体試料導入装置
}

\section{A New Sample Introduction System of Mass Spectrometer for a Very Small Amount of Gas Mixtures}

\author{
棋田勉* \\ Tutomu Makita \\ (1959年 1 月16日受理)
}

\begin{abstract}
A sample reservoir with the capacity of about $30 \mathrm{ml}$ contains a very small amount of sample at about 10 $\mu \mathrm{Hg}$. At first the upper end of the reservoir is communicated with the ionization chamber through a leak. After a given short time interval the lower end of the reservoir is communicated with reservoir containing a liquid, preferably mercury, and the liquid begins to flow into the reservoir at a rate which is a definite function of time. If now the scanning is performed with a definite time schedule, it may easily be proved that the height of the peak corresponding to a given substance is proportional to its initial partial pressure, which is a necessary condition for the exact analysis of the gas mixtures.

The smaller the sample reservoir, the more pronounced is the change with time in relative concentrations of the substances with different molecular weights. But a proper choice of the time function for the flow-in rate of the liquid and the scanning beginning with ions of lighter component, can largely compensate this tendency.

A preliminary test of the present method of analysis for a very small amount of sample was performed with a $\mathrm{Ne}+\mathrm{N}_{2}$ mixture contained in the 3 litre reservoir attached to a CEC 21-401 mass spectrometer. The usual macro-analysis and the micro-analysis of the sample were repeated several times alternately. The results obtained with the two kinds of analysis agreed within $\pm 0.5 \%$.
\end{abstract}

\section{1. 通常の醇量分析}

すでに周知のことであるが，参考のために，混合気 体試料を分析するために通常使用されている試料導入 装置抢よび必要な最小限の試料量などについてのべる。 正確に質量分析を行うためには，イオンビーム走査 中の試料留内圧力の減少をできるだけ小さくしなけれ ばならないので, 試料留の容䅡を $3 \sim 5 l$ K大きくつく り，ガス・リークを通る試料量は例宎ば ${ }^{20} \mathrm{Ne}$ につい て $0.2 \mathrm{ml} / \mathrm{sec}$. の程度にしてある。したがって圧力の 減少は $\mathrm{n}$ フブタンの場合でたとえば $0.15 \% / \mathrm{min}$ 程度 である。

試料留中の各成分の分圧は $5 \mu \mathrm{Hg}$ 程度以上である ことが望ましい。分圧が女まり小さいと，記録した質
量スペクトルのピークのらちの最高のものでも10 division 以下になって分析の精度がわるくなる。

したがって, 正確に分析するために必裂な試料の最 小量は，2成分試料の場合に，われわれのところの CEC 21-401質量分析計では $4 \times 10^{-2} \mathrm{ml}$ NTP の程度 である。

さて, 1 回の分析で走査に10分間かかるとすると, この間に試料留からイオン源に流れる試料は全体の約 $1 \%$ であるら，残った $99 \%$ は普通は排気して充てる ことになる。ではこの正味 $1 \%$ の試料量だけで質量分 析をすることはできないだろうか。このためにはもち ろん特別の工夫が要るが, 次にのべるわれわれの微量 気体試料分析法はその一つの解法である。

CEC 21-101質量分析計では, 指導書ど括り以操作す 